\title{
NASOALVEOLAR CYST: A RARE ENTITY
}

Anshul Bansal ${ }^{1}$, Parul Bansal2,

HOW TO CITE THIS ARTICLE:

Anshul Bansal, Parul Bansal, "Nasoalveolar cyst: a rare entity". Journal of Evolution of Medical and Dental Sciences 2013; Vol2, Issue 40, October 07; Page: 7777-7780.

ABSTRACT: Nasoalveolar cyst is a rare, non odontogenic cyst that constitute about $0.7 \%$ of all the jaw cysts. It is a soft tissue cyst present extraosseous as a slowly enlarging mass in the region of nasal ala. This paper presents a case of nasoalveolar cyst with focus on its clinical, radiological and histological features along with its surgical removal procedure.

KEY WORDS: Nasoalveolar cyst, non odontogenic cyst, nasal ala.

INTRODUCTION: Nasoalveolar cysts are less commonly occurring non odontogenic cysts of soft tissues. It was first described by Zuckerkandl ${ }^{1}$. These cysts unless infected, presented as painless slowly enlarging mass resulting in swelling around the nasal vestibule and upper lip leading to facial asymmetry and infrequently nasal stuffiness ${ }^{1}$. Though these are soft tissue cysts and are situated extraosseous, they may cause bone destruction. With the increasing size, nasoalveolar cysts may impinge on the anteroinferior turbinate and push against the septum. Long standing pressure may cause erosion of the nasal floor or premaxilla. This paper report a case of NAC present on left side of the face in a female patient which was managed successfully by surgical excision.

CASE REPORT: A 51 year old female presented with chief complain of facial asymmetry because of presence of mass on the left side of her nose that had been slowly increasing in size for several years. The patient could not recall any history of surgery or trauma. Anterior rhinoscopic examination revealed a fluctuant, well circumscribed, rounded soft tissue mass of dimension $2.5 \times 3 \mathrm{~cm}$ that protruded to the anterior nasal vestibule in the left superior gingival region and at the base of the left mesial aperture (fig 1). The left half of the upper lip had been altered by the cyst.

On aspiration straw coloured fluid was found. CT of paranasal sinuses revealed presence and extension of the lesion on the left side of the nose (fig 2a) and bone resorption in the area of anterior surface of maxilla (fig 2b). Diagnosis was made as nasoalveolar cyst. Surgical excision of cyst (enucleation) was planned under general anaesthesia. Patient's medical history was unremarkable. Treatment was explained to the patient and consent was obtained.

A $4 \mathrm{~cm}$ incision was made from mid line in the gingivolabial fold over the convexity of the swelling which was followed by blunt and sharp dissection to free the lesion from the surrounding tissues (fig 3). During procedure the nasal floor lining was perforated which was sutured after complete excision. Immediately after the procedure remarkable decrease in the swelling extra orally was noticed. There were no postoperative complications.

Microscopic examination revealed that the cyst wall was lined with low cuboidal epithelium at places and pseudostratified columnar epithelium at other places. No reoccurrence has been reported after 3 months of excision. 
DISCUSSION: Nasoalveolar cyst is a non odontogenic soft tissue lesion of the nasoalveolar region i.e. lateral to anterior maxillary area between upper lip and nasal aperture. It was first described by Zuckercandl ${ }^{1}$. It is synonymous with nasoalveolar cyst, nasal vestibule cyst, Klestadt's cyst, mucoid cyst of the nose. It is a benign type of lesion which remains asymptomatic for years and usually become symptomatic when they grow and indent the overlying mucosa or become infected. Infected cyst may become swollen and tender. The lesion may spontaneously rupture and drain nasally, orally or even though rarely, via a cutaneous fistula.

NACs constitute $0.7 \%$ of all the jaw cysts and are more frequently seen in women, black race and in $4^{\text {th }}$ to $5^{\text {th }}$ decade of life. ${ }^{1}$ NAC are occurring mostly unilaterally and are more common on the left side. Bilateral incidence has been reported in $10-11.2 \%$ of cases ${ }^{2}$. Through they are developmental in origin; clinical manifestations do not exist until adulthood. ${ }^{3}$

Regarding pathogenesis of nasolabial cysts there are three theories for the formation of the cyst $^{4}$. (1) The cyst is formed embryologically by detention cells in the maxilla, medial, and lateral nasal wall. This theory is widely accepted and given by Klestadt. (2) The cyst is formed embryologically by detention cells from inferior nasolacrimal channel redundant cells ${ }^{2}(3)$. The cyst is formed embryologically by detention cells from the inferior nasolacrimal channel ectodermal cells. Exposure to trauma may accelerate the formation of the cyst.

Clinically the cyst is best palpated bimanually with a finger in the floor of the nose and other in the sublabial sulcus. The localization and structure of the cyst can be demonstrated with CT scan; especially the relation of the cyst to the surrounding tissues and assessment of bony erosion can be imaged.

The differential diagnosis should include odontogenic, developmental and neoplastic lesions ${ }^{5}$. Another possible cyst of non odontogenic origin is epidermoid or epidermal inclusion cyst. As opposed to normal pink or bluish coloration of nasolabial cyst, this cyst is yellow hue in colour. An example of neoplasm that needs to be excluded in this area is minor salivary gland tumors. As oppose to nasolabial cyst, minor salivary gland tumors are usually non fluctuant. There is a reported case using MRI for diagnosing nasolabial cyst to differentiate it from minor salivary gland tumor. In minor salivary gland tumor, MRI will show contrast enhancement of internal lesion compared to non enhancement in nasolabial cyst. Computed tomography is able to demonstrate the soft tissue nature of the cyst as well as bony involvement. As the cyst is benign in nature, there is no bony erosion other than expansile lesion causing thinning of the bone ${ }^{6}$.

Microscopically, this cystic structure is composed of a fibrous capsule with an unremarkable layer of pseudo stratified columnar epithelium ${ }^{1}$, 3 . In our case, the cyst was lined by low cuboidal cells at places and pseudostratified epithelium at other places, possibly owing to the fact that pluripotent embryonic epithelial nests have the capacity of transformation from respiratory to squamous epithelium ${ }^{3}$.

The current recommended treatment of nasolabial cyst is complete excision via sublabial incision ${ }^{5}$ which can be performed under LA $^{5}$, however we used general anaesthesia as the patient was anxious. The incision should be made in the gingivobuccal fold over the convexity of the swelling, rather than through the mucoperiosteum. Recurrence after treatment has not been reported up to now and malignant degeneration had been determined in one case only ${ }^{5}$.

Other mode of treatment that had been described is simple aspiration, injections with a sclerosing agent, destruction by cautery. However these methods are associated with high 
recurrence rates. Marsupialization of cyst had been previously reported to have high recurrence rate. Alternatively endoscopic cyst marsupialization via transnasal approach can be considered for treatment ${ }^{3}$.

\section{REFERENCES:}

1. El-Din K, El-Hamd AA. Nasolabial cyst: A report of eight cases and review of literature. J Laryngol otol 1999; 113:747-49.

2. Wesley RK, Scanell T, N athan LE. Nasolabial Cyst: presentation of a case with a review of literature. J Oral Maxillofacial Surgery. 1984; 42:188-192.

3. Ulubil SA, Aslan I, Basaran B, Baserer N, Radiology Quiz case 2. Arch Otolaryngol Head Neck surgery 2003; 129:374-77.

4. Sahin C. Case Report- Nasolabial Cyst. Case reports in medicine 2009; 56:114-5.

5. Lopaz-Rios F, Lassaletta Atienza L, Domingo-Carrasso C, Marlinez-Telllo FJ. Nasoalveolar cyst, Report of a case with apocrine change. Oral Surgery Oral Medicine Oral Path Oral Radio Endod 1997:84:202-04.

6. Zahituddin.Z. Nasolabial cyst: Presentation and Management. Int J of Otolaryng 2009; 9:3640.

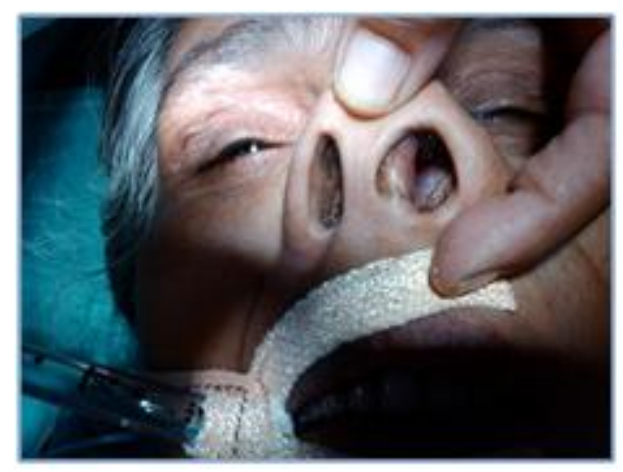

\section{Figure 1: Cyst protruding in the anterior nasal}

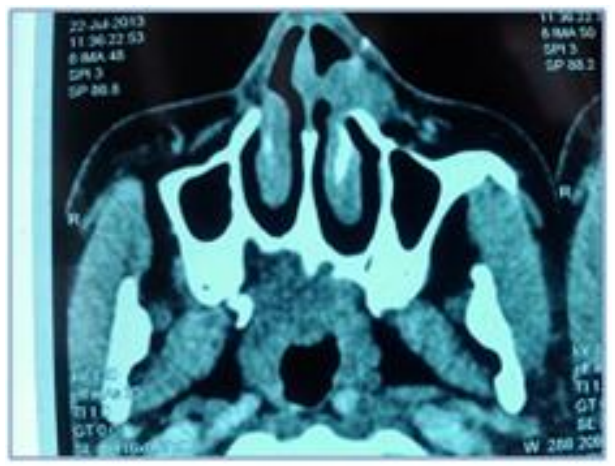

Figure 2a: CT axial section revealing extension of the cyst. 


\section{CASE REPORT}

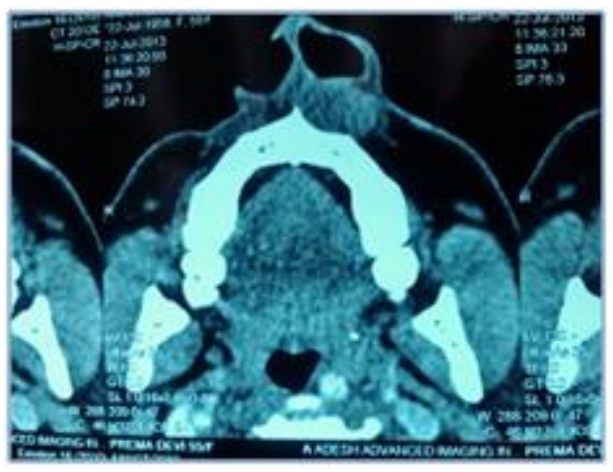

Figure 2b: CT axial section revealing resorption of anterior surface of maxilla.

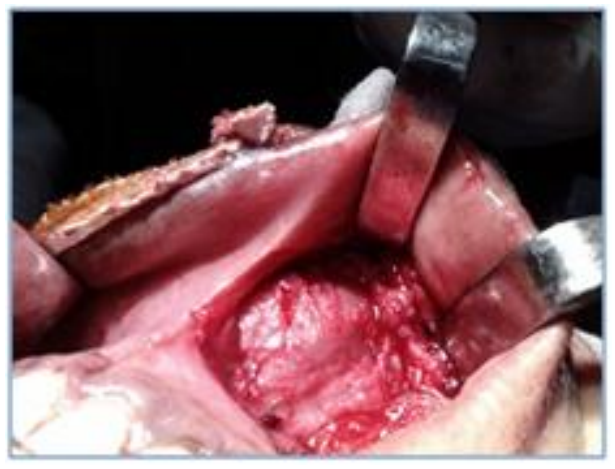

Figure 3: Sublabial Incision exposing cyst in situ.

\section{AUTHORS:}

1. Anshul Bansal

2. Parul Bansal

\section{PARTICULARS OF CONTRIBUTORS:}

1. Assistant Professor, Department of Otorhinolaryngology and Head Neck Surgery, Adesh Institute of Medical Sciences, Adesh University, Bathinda, Punjab.

2. Reader, Department of Conservative Dentistry \& Endodontics, Subharti Dental College, Swami Vivekanand Subharti University, Meerut, Utter Pradesh (India).

\section{NAME ADDRESS EMAIL ID OF THE} CORRESPONDING AUTHOR:

Dr. Anshul Bansal,

C/o Mr. Suresh Gupta,

58/6, Jagriti Vihar,

Opposite LLRM Medical College,

Meerut, Utter Pradesh.

Email-dranshulparul@gmail.com

docparulbansal@gmail.com

Date of Submission: 20/09/2013.

Date of Peer Review: 21/09/2013.

Date of Acceptance: 25/09/2013.

Date of Publishing: 07/10/2013. 